\title{
Hindi translation of Berlin questionnaire and its validation as a screening instrument for obstructive sleep apnea
}

\author{
Ravi Gupta, Ramjan Ali, Mohan Dhyani, Sourav Das, Ashwini Pundir \\ Department of Psychiatry and Sleep Clinic, Himalayan Institute of Medical Sciences, Dehradun, Uttarakhand, India
}

\section{ABSTRACT}

Background: Obstructive sleep apnea (OSA) is a fairly common problem with adverse health consequences. However, any screening questionnaire is not available in Hindi to screen sleep apnea. Materials and Methods: Subjects undergoing video-synchronized in laboratory attended polysomnography were requested to participate in this study. They were screened with the help of Hindi version of Berlin questionnaire (BQ). Outcome of the BQ was tested against the gold standard polysomnography. Descriptive statistics, sensitivity, specificity, positive predictive value (PPV), and negative predictive value (NPV) of Hindi version were calculated. Results: 38 patients with polysomnography diagnosed OSA and 12 controls were included in this study. Average body mass index (BMI) in the OSA group was $33.12+6.66 \mathrm{~kg} / \mathrm{m}^{2}$ whereas in the control group BMI was $25.01+4.20 \mathrm{~kg} / \mathrm{m}^{2}$. Average age in the OSA group was $48.9+10.2$ years whereas the control group was older $(56.9+12.1$ years). Hindi version had sensitivity of $89 \%$ and specificity of $58 \%$. PPV of the instrument was 0.87 whereas NPV was 0.63 . Conclusion: Hindi version of BQ is a valid tool for screening the OSA irrespective of the literacy status of the subjects.

Key words: Hindi, obstructive-sleep-apnea, screening

\section{Introduction}

Obstructive sleep apnea (OSA) is a repetitive obstruction or closure of the upper airway, causing a partial or complete disturbance in breathing during sleep. ${ }^{[1]}$ Situation is not very different in India as a survey from North India had estimated the prevalence of OSAs at 3.6\% (males and females being $4.9 \%$ and $2.1 \%$, respectively) and OSA was $13.7 \%{ }^{\left[{ }^{[2]}\right.}$ Thus, the prevalence for OSA in India is close to that of its prevalence in the West.

Patients with OSA are at a higher risk for several comorbidities such as metabolic syndrome, diabetes

\section{Address for correspondence:}

Dr. Ravi Gupta, Department of Psychiatry and Sleep Clinic, Himalayan Institute of Medical Sciences, Swami Ram Nagar, Jolly Grant, Dehradun - 248 016, Uttarakhand, India.

E-mail: sleepdoc.ravi@gmail.com

\begin{tabular}{|l|l|}
\hline \multicolumn{2}{|c|}{ Access this article online } \\
\hline Quick Response Code: & Website: \\
\hline & www.ruralneuropractice.com \\
\cline { 2 - 2 } & \\
\hline
\end{tabular}

mellitus, hypertension, gastroesophageal reflux disease, stroke, cardiovascular disease, cognitive impairment, and occupational and motor vehicle accidents. ${ }^{[3,4]}$ Despite the several adverse health consequences of OSA, it remains largely undiagnosed in the general population. Up to $85 \%$ of those with OSA have not been diagnosed with the disorder. ${ }^{[5]}$

The best person to pick the OSA can be the primary care physician or the family physician, who are the most frequent contact points for the patients with OSA. ${ }^{[6]}$ Currently, polysomnography is the gold standard for the evaluation of OSA; however, because of its expensiveness and the limitations of its access, it cannot be used regularly as the screening test. ${ }^{[7]}$ The difficulty involved in obtaining an OSA diagnosis has led to the development of questionnaires which can assist healthcare providers in the recognition of OSA. One of these screening questionnaires is

This is an open access article distributed under the terms of the Creative Commons Attribution-NonCommercial-ShareAlike 3.0 License, which allows others to remix, tweak, and build upon the work non-commercially, as long as the author is credited and the new creations are licensed under the identical terms.

For reprints contact: reprints@medknow.com

How to cite this article: Gupta R, Ali R, Dhyani M, Das S, Pundir A. Hindi translation of Berlin questionnaire and its validation as a screening instrument for obstructive sleep apnea. J Neurosci Rural Pract 2016;7:244-9. 
Berlin questionnaire (BQ) $\cdot^{[8]}$ The $\mathrm{BQ}$ is an instrument validated to use in the Western population to determine the occurrence of risk factors for OSA/ hypopnea syndrome and is originally available in English. ${ }^{[8]}$ It has been translated into various languages throughout the world..$^{[9-12]}$ In India, where majority of the population is Hindi speaking, it is essential to translate $\mathrm{BQ}$ into Hindi to recognize OSA, especially at the Primary health care level. Thus, this study was planned to translate the BQ in Hindi and validate it against the standard overnight video-synchronized polysomnography.

\section{Materials and Methods}

This study was conducted in the Sleep Clinic of a teaching hospital after obtaining permission of Institutional Ethics Committee. Subjects who underwent the level-1 polysomnography in the sleep laboratory of the institute for suspected OSA or unexplained chronic insomnia were approached for participation in the study after explaining them the rationale of the study. Those patients who gave consent for participation were included. Subjects having active respiratory or cardiac problems that could interfere with the polysomnography or administration of $\mathrm{BQ}$ were excluded from the study.

After inclusion in the study, demographic details of the subjects were recorded. Thereafter, the Hindi version $\mathrm{H} 4$ of BQ was read aloud to control for literacy status. Wherever any of the subjects experienced any difficulty in understanding the language, it was explained to the patient and that problem was noted.

Hypertension was defined as the systolic blood pressure (BP) of $140 \mathrm{mmHg}$ or diastolic BP of $90 \mathrm{mmHg}$ or when the subjects had documented systemic hypertension in medical records and were on antihypertensive medication. ${ }^{[13]}$ Height and weight were measured using stadiometer (within $1 \mathrm{~cm}$ ) and weighing machine (accuracy of $+1 \mathrm{~kg}$ ). Body mass index (BMI) was calculated manually.

\section{Berlin questionnaire}

The BQ is composed of three categories of symptoms, five questions are related to snoring and cessation of breathing in category 1 , four questions are related to daytime sleepiness in category 2; there is a question about high $\mathrm{BP}$ and also a question about the BMI in category $3 .{ }^{[8]}$ In category 1 and 2, high risk was defined as persistent symptoms (>3-4 times/week). In category 3 , high risk was defined by the presence of hypertension $(>140 / 90 \mathrm{mmHg}$ or use of medication) or a BMI $>30 \mathrm{~kg} / \mathrm{m}^{2}$. Patients and control subjects were classified as having a high risk for OSA if scores were positive on two or more categories. ${ }^{[8]}$ The questionnaire has demonstrated the Cronbach's correlations of $0.86-0.92$ with sensitivity of $86 \%$, specificity of $77 \%$, positive predictive value (PPV) of $89 \%$, negative predictive value (NPV) of $72 \%$, and a likelihood ratio of 3.79. ${ }^{[8]}$

\section{Translation procedure}

The scale in English was translated into Hindi by two bilingual personages individually as per the guidelines. ${ }^{[14]}$ The two versions $\mathrm{H} 1$ and $\mathrm{H} 2$ were then matched, discussed in the presence of a third bilingual person, and with consensus, a Hindi translated version $\mathrm{H} 3$ was produced. The version $\mathrm{H} 3$ was then translated back to English by two bilingual personages individually to get version B1 and B2. After a process of discussion and matching, a final back-translated version B3 was arrived at in consultation with the third bilingual person. The back-translated version B3 was matched with the original BQ.

The minor discrepancies between the B3 with original BQ were corrected. This led to some corroborating corrections in H3 leading to a final translated Hindi version the $\mathrm{H} 4$. The version $\mathrm{H} 4$ was agreed by all translators and an author having expertise in Sleep Medicine (team of 6 persons) to be the final Hindi translation of the original $\mathrm{BQ}$ and was employed for testing the validity and specificity. Word or a phrase of an item or the response which, most of the study subjects found difficult to understand was changed to make it simpler and thus, version $\mathrm{H} 5$ was reached.

\section{Polysomnography}

Overnight 24-channel video-synchronized polysomnography was done in the sleep laboratory using Alice-5 Diagnostic Sleep System (Philips Respironics). Each of the subjects was explained the procedure in detail beforehand and was acclimatized to the environment of sleep laboratory. The study was conducted during the night time. Raw data were scored according to the guidelines proposed by the American Academy of Sleep Medicine by a trained sleep physician. ${ }^{[15]}$ Subjects who were found to have OSA served as cases whereas subjects with negative polysomnographic report for OSA were considered as controls.

\section{Statistical analysis}

Statistical analysis was done with the help of SPSS version 20.0 (IBM Corp. Released 2011. IBM SPSS Statistics for Windows, Version 20.0. Armonk, NY: IBM Corp). Descriptive statistics was calculated. The sensitivity and specificity were formulated using a $2 \times 2$ contingency 
table. Results obtained from the Hindi version of $B Q$ were validated against the results of polysomnography.

\section{Results}

In this study, a total of 50 subjects were included out of which, $70 \%$ were male. Average age of the male was $48.2+11.6$ years which was comparable to the females $(47.8+9.9$ years $)(t=0.1 ; P=0.9)$. The group was dominated by the subjects with OSA (76\%) as diagnosed by polysomnography. Other subjects included in this study were suffering from chronic unexplained insomnia. OSA on polysomnography was seen in $77.7 \%$ men and $71.4 \%$ women in this group $\left(\chi^{2}=0.22 ; P=0.63\right)$. Average BMI in the OSA group was $33.12+6.66 \mathrm{~kg} / \mathrm{m}^{2}$ whereas in the control group BMI was $25.01+4.20 \mathrm{~kg} / \mathrm{m}^{2}$. Average age in the OSA group was $48.9+10.2$ years whereas the control group was older $(56.9+12.1$ years $)$.

\section{Translation procedure}

No major linguistic issue was noticed during the forward translation and back translation, i.e. H1, H2, $\mathrm{H} 3$ and $\mathrm{B} 1, \mathrm{~B} 2$, and $\mathrm{B} 3$. B3 was close to the original questionnaire. However, after it has been given to the study subjects, some changes had to be made to convey the intended content of the item. First, item 4 had the word "how often" which was translated to "kitni baar" in Hindi. However, without the responses associated with this item, it became difficult to ascertain the "time frame" for which the frequency was to be ascertained. However, it was left as such because it matched with the language of original questionnaire and subjects included in the study did not find it difficult. Second, in item 7 of the original questionnaire, "after sleep" was translated to "sone ke baad." However, subjects find it difficult to understand and hence, in the H5 version, it was changed to "sokar uthane ke baad." Third, in item numbers 7 and 8 phrase "tired and fatigued" and "tired, fatigued, and not up to par" were translated to one word "thakaa huyaa" as we could not find any specific Hindi word for both these terms. Finally, in item number 10, H4 version had "uchcha rakta chaap" for the "high BP" in the original questionnaire. However, many subjects reported difficulty in understanding it and hence "high BP" was mentioned in Hindi script in the parenthesis in version H5 [Annexure 1].

\section{Psychometric properties of Hindi version}

Table 1 depicts the data of the outcome on the $\mathrm{H} 5$ version of $\mathrm{BQ}$ where the polysomnography is considered as the gold standard. This table showed that the Hindi version had a sensitivity of $89 \%$ and
Table 1: Outcome on the Hindi version of Berlin questionnaire with reference to overnight polysomnography

\begin{tabular}{lcc}
$\begin{array}{l}\text { Berlin } \\
\text { questionnaire }\end{array}$ & \multicolumn{2}{c}{$\begin{array}{c}\text { Video-synchronized attended in } \\
\text { laboratory polysomnography (\%) }\end{array}$} \\
\cline { 2 - 3 } & OSA (AHI >5) & No OSA (AHI $\leq 5)$ \\
\hline High risk for OSA & $34(89.4)$ & $5(41.6)$ \\
Low risk for OSA & $4(10.6)$ & $7(58.4)$ \\
Total & 38 & 12 \\
\hline
\end{tabular}

OSA: Obstructive sleep apnea, AHI: Apnea-hypopnea index

specificity of $58 \%$. PPV of the instrument was 0.87 whereas NPV was 0.63 .

\section{Discussion}

This study shows that Hindi translation of the BQ may be used for the screening of OSA in general population as we have included subjects with and without clinical suspicion of OSA. It has been found to be a valid tool as compared to the overnight polysomnography. In this study, we have found that it was sensitive.

Like the present study, previous studies have also found the male predominance in the OSA group. ${ }^{[10,16]}$ We observed a difference in the age and the BMI between the cases and controls and this was related to the fact that controls had clinically unexplained chronic insomnia and study was not done for the suspected OSA. This also relates to the fact that control group was older than the OSA group in this study. The control group in one of the studies was younger with lesser BMI. ${ }^{[16]}$ This was related to the fact that polysomnography in all patients was done for the suspected OSA in that study. ${ }^{[16]}$

The sensitivity of the Hindi version of $B Q$ was found to be $89 \%$. The translated version of $B Q$ in other language has found comparable sensitivity. Sensitivity in the earlier translated versions had varied from 59\% to $97 \%$ depending upon the severity of OSA and control group included in the study. ${ }^{[9-12]}$ One Indian study that has used the modified BQ used both Hindi and English versions and found that the sensitivity was $86 \% \cdot{ }^{[16]}$ It has been found that sensitivity increases with increasing severity of OSA, which is often measured by the apnea-hypopnea index. ${ }^{[12]}$ We did not study the differential sensitivities among different grades of OSA because of the small number of subjects; however, this should be done in future.

Similarly, specificity has been reported to vary between $17 \%$ and $90 \%$ among different studies. ${ }^{[9-12,16]}$ This variation is related to the fact that $\mathrm{BQ}$ is a self-reported 
questionnaire and many patients with OSA are not aware of their symptoms, hence, they respond to items differently as seen in one study. ${ }^{[10]}$ High degree of specificity was observed when some assistance was provided to the patients to fill the questionnaires. ${ }^{9,11,16]}$ Poor specificity could be related to the design of the questionnaire. Low degree of correlation has been found between snoring or excessive daytime sleepiness and OSA on sleep study. ${ }^{[17-19]}$ BQ has four items that address the snoring and two that asks for daytime fatigue or sleepiness. This is why its use as a diagnostic tool has been questioned, while has been advocated for the screening. ${ }^{[18]}$ We have found the specificity was $58 \%$ which was lesser than some of the studies mentioned above and this could be related to the fact that items were answered by the subjects themselves. Thus, it appears that with the assistance of bed partner, BQ may be used as a screening tool with higher specificity. ${ }^{[20]}$

During the translation, we found some cultural issues with the use of some of the phrases and hence, the final version showed some minor deviation from the original scale, however, conveyed the same information as intended in the original instrument. This approach has been advocated in one of the papers addressing this issue and is acceptable. ${ }^{[14]}$

However, small sample size, especially that of the control group was a limitation. Similarly, this study included only adult patients and hence, validity of this questionnaire in the pediatric population is not established. We also did not check the psychometric properties among different groups based upon the severity of OSA.

\section{Conclusion}

It has been found that Hindi version of $B Q$ is a valid tool to screen OSA with a high degree of sensitivity. All the subjects, irrespective of their literacy status, did not find any difficulty in understanding the items or the responses of this questionnaire.

\section{Acknowledgment}

We are thankful to Dr. NC. Netzer for allowing us to translate the Berlin questionnaire in Hindi.

\section{Financial support and sponsorship}

Nil.

\section{Conflicts of interest}

There are no conflicts of interest.

\section{References}

1. American Academy of Sleep Medicine. International Classification of Sleep Disorders. $3^{\text {rd }}$ ed. Darian, IL: American Academy of Sleep Medicine; 2014.

2. Sharma SK, Kumpawat S, Banga A, Goel A. Prevalence and risk factors of obstructive sleep apnea syndrome in a population of Delhi, India. Chest 2006;130:149-56.

3. De Torres-Alba F, Gemma D, Armada-Romero E, Rey-Blas JR, López-de-Sá E, López-Sendon JL. Obstructive sleep apnea and coronary artery disease: From pathophysiology to clinical implications. Pulm Med 2013;2013:768064.

4. Terán-Santos J, Jiménez-Gómez A, Cordero-Guevara J. The association between sleep apnea and the risk of traffic accidents. Cooperative Group Burgos-Santander. N Engl J Med 1999;340:847-51.

5. Young T, Evans L, Finn L, Palta M. Estimation of the clinically diagnosed proportion of sleep apnea syndrome in middle-aged men and women. Sleep 1997;20:705-6.

6. Mold JW, Quattlebaum C, Schinnerer E, Boeckman L, Orr W, Hollabaugh K. Identification by primary care clinicians of patients with obstructive sleep apnea: A practice-based research network (PBRN) study. J Am Board Fam Med 2011;24:138-45.

7. Abrishami A, Khajehdehi A, Chung F. A systematic review of screening questionnaires for obstructive sleep apnea. Can J Anaesth 2010;57:423-38.

8. Netzer NC, Stoohs RA, Netzer CM, Clark K, Strohl KP. Using the Berlin questionnaire to identify patients at risk for the sleep apnea syndrome. Ann Intern Med 1999;131:485-91.

9. Saleh AB, Ahmad MA, Awadalla NJ. Development of Arabic version of Berlin questionnaire to identify obstructive sleep apnea at risk patients. Ann Thorac Med 2011;6:212-6.

10. Yunus A, Seet W, Mohamad Adam B, Haniff J. Validation of the Malay version of Berlin questionnaire to identify Malaysian patients for obstructive sleep apnea. Malays Fam Physician 2013;8:5-11.

11. Amra B, Nouranian E, Golshan M, Fietze I, Penzel T. Validation of the persian version of berlin sleep questionnaire for diagnosing obstructive sleep apnea. Int J Prev Med 2013;4:334-9.

12. Popevic MB, Milovanovic A, Nagorni-Obradovic L, Nešic D, Milovanovic J, Milovanovic AP. Screening commercial drivers for obstructive sleep apnea: Translation and validation of Serbian version of Berlin Questionnaire. Qual Life Res 2015;PubMed PMID: 26231590. [Epub ahead of print].

13. Go AS, Mozaffarian D, Roger VL, Benjamin EJ, Berry JD, Borden WB, et al. Heart disease and stroke statistics-2013 update: A report from the American Heart Association. Circulation 2013;127:e6-245.

14. Sousa VD, Rojjanasrirat W. Translation, adaptation and validation of instruments or scales for use in cross-cultural health care research: A clear and user-friendly guideline. J Eval Clin Pract 2011;17:268-74.

15. Berry RB, Brooks R, Gamaldo CE, Harding SM, Lioyd RM, Marcus CL, et al. The AASM Manual for Scoring of Sleep and Associated Events: Rules, Terminology and Technical Specifications. Ver. 2. Darien, IL: American Academy of Sleep Medicine; 2015.

16. Sharma SK, Vasudev C, Sinha S, Banga A, Pandey RM, Handa KK. Validation of the modified Berlin questionnaire to identify patients at risk for the obstructive sleep apnoea syndrome. Indian J Med Res 2006;124:281-90.

17. Bearpark H, Elliott L, Grunstein R, Cullen S, Schneider H, Althaus W, et al. Snoring and sleep apnea. A population study in Australian men. Am J Respir Crit Care Med 1995;151:1459-65.

18. Jennum P, Sjøl A. Epidemiology of snoring and obstructive sleep apnoea in a Danish population, age 30-60. J Sleep Res 1992;1:240-244.

19. Sforza E, Chouchou F, Pichot V, Herrmann F, Barthélémy JC, Roche F. Is the Berlin questionnaire a useful tool to diagnose obstructive sleep apnea in the elderly? Sleep Med 2011;12:142-6.

20. Sagaspe P, Leger D, Taillard J, Bayon V, Chaumet G, Philip P. Might the Berlin sleep questionnaire applied to bed partners be used to screen sleep apneic patients? Sleep Med 2010;11:479-83. 


\section{बर्लिन प्रश्नावली @ 1997 IONSLEEP (Annexure)}

1. कपया निम्न प्रश्नों कें उत्तर दें-

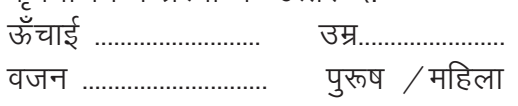

2. क्या आपको खर्राटे आते है ?

$\mathrm{O}$ हाँ

$\mathrm{O}$ नहीं

$\mathrm{O}$ पता नहीं

अगर आप खर्राटे लेते हैं.-

3. तो आपके खर्राटे-

$\mathrm{O}$ साँस की आवाज सें थोडा तेज होते हैं।

0 बात करने की आवाज जितना तेज होते हैं।

$\mathrm{O}$ बात करने की आवाज से ज्यादा तेज होते हैं।

$\mathrm{O}$ बहुत तेज होते है। पास वाले कमरें में सुने जा सकते हैं।

4. आप कितनी बार खर्राटे लेते हैं -

$\mathrm{O}$ करीब - करीब हर दिन

$\mathrm{O}$ सप्ताह में $3-4$ बार

$\mathrm{O}$ सप्ताह में $1-2$ बार

$\mathrm{O}$ महीने में $1-2$ बार

$\mathrm{O}$ कभी नही या करीब-2 कभी नही

5. क्या कभी आपके खर्राटों की वजह से दूसरो को परेशानी हुई है ?

$\mathrm{O}$ हाँ

$\mathrm{O}$ नहीं

6.

क्या कभी किसी ने घ्यान दिया कि नींद में आपकी सॉस रूक जाती है ?

$\mathrm{O}$ करीब -करीब हर दिन

0 सप्ताह में 3-4 बार

0 सप्ताह में $1-2$ बार

$\mathrm{O}$ महीने में $1-2$ बार

$O$ कभी नही या करीब-2 कभी नही

7. सोकर उठने के बाद भी कितनी बार आप थका हुआ महसूस करते हैं ?

$\mathrm{O}$ करीब-करीब हर दिन

$\mathrm{O}$ सप्ताह में 3-4 बार

0 सप्ताह में $1-2$ बार

$\mathrm{O}$ महीने में $1-2$ बार

$\mathrm{O}$ कभी नही या करीब-2 कभी नही

8. क्या आप जागते हुए थका हुआ महसूस करते हैं ?

$\mathrm{O}$ करीब-करीब हर दिन

$\mathrm{O}$ सप्ताह में 3-4 बार

$\mathrm{O}$ सप्ताह में $1-2$ बार

$\mathrm{O}$ महीने में $1-2$ बार

$\mathrm{O}$ कभी नही या करीब-2 कभी नहीं

9. क्या कभी आप वाहन चलाते हुए सो गए हैं या आपको झपकी आई है ?

$\mathrm{O}$ हाँ

$\mathrm{O}$ नहीं

अगर हाँ तो ऐसा कितनी बार होता है ?

$\mathrm{O}$ करीब-करीब हर दिन

$\mathrm{O}$ सप्ताह में $3-4$ बार

$\mathrm{O}$ सप्ताह में $1-2$ बार 
$\mathrm{O}$ महीने में $1-2$ बार

$\mathrm{O}$ कभी नही या करीब-2 कभी नही

10. क्या आपको उच्च रक्त चाप (हाई बी. पी.) है ?

$\mathrm{O}$ हाँ

$\mathrm{O}$ नहीं

बी. एम. आई. $>30 \mathrm{~kg} / \mathrm{m}^{2}$

$\mathrm{O}$ हाँ

$\mathrm{O}$ नही 